\title{
Türkiye’de Trafik Kazaları ve Sürücülerin Kazalardaki Payı
}

\author{
${ }^{1}$ Zeliha Çağla Kuyumcu, ${ }^{* 2}$ Hakan Aslan ${ }^{* 3}$ Meutia Ayuni Yose, ${ }^{* 4}$ Suhrab Ahadi \\ * 1, 2, ve ${ }^{3}$ Mühendislik Fakültesi, İnşaat Mühendisliği Bölümü, Sakarya Üniversitesi, Türkiye \\ ${ }^{*}{ }^{4}$ Mühendislik Fakültesi, Jeodezi Bölümü, Jawzjan Üniversitesi, Afganistan
}

\section{Özet}

Dünya'da her yıl trafik kazaları nedeniyle 1,35 milyon kişi hayatını kaybetmekte, 20-50 milyon kişi ise yaralanmaktadır. Çocuk ve genç (5-29 yaş arası) ölüm nedenlerinin başında trafik kazaları gelmektedir. Savunmasız yol kullanıcıları olarak tanımlanan yayalar, bisikletliler, 2-3 tekerlekli motosiklet kullanıcıları tüm kazalarda hayatını kaybedenlerin yüzde ellisini oluşturmakta olup, düşük gelirli ülkelerin payı yüksek gelirli ülkelere göre daha fazla olmaktadır [1]. Trafik kazalarının neden olduğu bu kayıpların azaltılması için bilimsel çalışmalara, bulgulara ve sonucunda önlemlere gereksinim duyulmaktadır. Elimizde bulunan raporlara, verilere göre trafik kazalarında hatalı görünen başlıca öge sürücülerdir. Bu çalışmada, Türkiye'de gerçekleşen kazaların dağılımı ve literatürde yer alan kazalarla ilgili yapılan çalışmalar irdelenmiş, veri madenciliği konseptinde yapılması planlanan çalışmanın altlı̆̆ oluşturulmuştur.

Anahtar Kelimeler: Trafik kazaları, sürücü davranışı, sürücü hataları, veri madenciliği.

\begin{abstract}
Every year, 1.35 million people die and 20-50 million people are injured in the world due to traffic accidents. Traffic accidents are the leading cause of death fo children and adolescents (aged 5-29). pedestrians, cyclists, 2-3 wheeled motorcycle users, defined as vulnerable road users. This accounts for the 50 percent of the total death toll for those who lost their lives in all accidents. It must be noted that the share of low-income countries is higher than high-income countries [1]. Scientific studies and related findings and consequently precautions are needed in order to reduce these losses caused by traffic accidents. According to the reports and data available, the main factor that appears to be main contributor in traffic accidents is the drivers. In this study, the distribution and structure of the accidents occurred in Turkey have been analysed through the studies in the literature and, the base of the planned research in data mining concept has been established.
\end{abstract}

\section{Giriş}

Trafik kazaları nedeniyle oluşan yaralanma ve ölümleri azaltmak, yol güvenliğini arttırmaya yönelik önlemlerin alınması ile mümkün olabilmektedir. Bu önlemlerin önceliğini belirlemek için trafik kaza verilerinden çeşitli ilişkiler ortaya çıkarılarak kaza olasılıklarını belirleme ve yüksek olasılıkların oluştuğu durumları ortaya çıkarıp gerekli önlemlerin alınmasına yardımcı olmak için dünyanın her yerinde çeşitli çalışmalar yapılmış, yapılmaya da devam edilmektedir. Büyük veri setlerinden anlamlı ilişkiler çıkarabilmek için kullanılan metotlardan biri olan veri madenciliği

*Corresponding author: Address: Faculty of Engineering, Department of Civil Engineering Sakarya University, 54187, Sakarya TURKEY. E-mail address: haslan@sakarya.edu.tr, Phone: +902642955752 
teknikleri, trafik kazaları analizlerinde güçlü bir yöntem olarak karşımıza çıkmaktadır.

Yu ve diğerlerinin, Wisconsin'de yaptığı çalışmada veri madenciliği tekniklerinde yer alan apriori algoritması kullanılarak, trafik kazalarının oluşumuna ve şiddetine etki eden faktörler arasında önemli birliktelik kuralları çıkarılmaya çalışılmıştır. Önceki çalışmalardan farklı olarak bu çalışma; çevresel, yönetimsel ve sürücü ve araç durumlarını içeren değişkenler barındırmaktadır. Çalışma sonuçlarından biri 16-29 yaş aralığındaki erkek sürücülerin fiziksel engelle ayrılmayan yollarda meydana gelecek kazalara karışma eğiliminde olduklarıdır. Başka bir sonuç ise; ölümlü kazaların daha çok kasaba (şehir merkezi dışı), maddi hasarlı kazaların ise daha çok şehir merkezlerinde meydana geldikleridir. Bu bulguların, yasal otoritelerin verimli karayolu güvenliği iyileştirme politikaları geliştirmelerine yardımcı olabileceği öngörülmektedir [2].

Shahverdy ve diğerlerinin yaptığı çalışmada, sürücüler; normal-güvenli, sinirli, dikkati dağınık, uykulu ve alkollü sürücü olarak beș sınıfa ayrılmıştır.

- Normal-güvenli sürücüler; riskli davranışları olmayan, uygun şekilde odaklanmış, ani manevralardan, güvenli olmayan şerit değişimlerinden kaçınan kişiler,

- Sinirli sürücüler; yolculuk süresini en aza düşürmeye çalışıp, bunun için ani şerit değiş̧irmeleri ve fren-gaz pedalı geçişleri gibi davranışlarda bulunan kişiler,

- Dikkati dağını sürücüler; hızlı sürücülere uygun tepki verememe, araç içinde ki nesneler ve telefonlarla, insanlar ya da olaylarla ilgilenen, bir şeyler yiyip içen, kişiler,

- Uykulu sürücüler; tekrarlı şekilde esneyen, gözlerini zor açı tutan, yavaş tepki veren, direksiyon tutmada zorlanan, aracı sarsan, seyrek fren yapan, hiz ve vites değişimlerini yavaş yapan, hız limitinden düşük hızda seyreden kişiler,

- Alkollü sürücüler, aracı şeritte tutamayan, ani hızlanan, güvenli olmayan şerit değişimleri yapabilen, tehlikeye karşı farkındalıkları önemli ölçüde düşük kişiler olarak tanımlanmıştır.

Bu çalışmada, yapay sinir ağları; dikkat dağınıklığı, uyuklama ve direksiyon tutma davranışı tespitinde uygulanmıştır. K-means kümeleme tekniklerinden sürücü tiplerini ayırmada faydalanılmıştır [3].

Alavi ve diğerlerinin yaptığı çalışmada, İran'da 2013-2015 yılları arasında ehliyet yenileme amacıyla tıbbi kontrolden geçmek için hastaneye gelen 800 otobüs ve kamyon sürücüsü ile anket çalışması yapılmıştır. Çalışma için ağır taşıt sürücülerinin seçilmesinin nedeni, bu sürücülerin diğer sürücülere kıyasla daha yüksek riskli kaza sınıfında olmalarıdır. Ankete katılan sürücüler, 2 yıl boyunca takip edilip, düzenli olarak ağır araç kullanmaları sağlanan kişiler olup, kazaya karışan sürücüler belirlenmiştir. Ankette yer alan sorular, davranış çeşitlerini ve diğer sürücülere risk oluşturma derecesini belirlemek için hazırlanmıştır. Çalışmanın bulgularına bakıldığında; yaş arttıkça kaza riskinin azaldığı, depresyonun trafik kaza olasılığını 2,4, takıntı bozukluğunun ise 2,7 kat arttırdığı görülmüştür. Ayrıca kaza yapan ve yapmayan sürücüler olarak ayrılan grupların sürücü davranışı, kasıtlı ihlal, dönme-manevra hatası, kasıtsız ihlal gibi davranışları açısından anlamlı farklılık gösterdiği, $t$ testi ile bulunmuştur. Kazalarda belirlenen iki temel faktörden biri sürücünün demografik diğeri sürücü davranış özellikleridir. Bu çalışmada trafik kazaları; zihinsel 
davranış özellikleri (zihinsel rahatsızlık gibi), kişilik özellikleri, sürücü yaşı gibi parametreler açısından incelenmiştir. Çalışma sonuçları, C ve D sınıfı ehliyete sahip kişilerde trafik kazaları oranlarının kontrol edilmesi ve ehliyet verme sürecinde gerekli düzenlemelerin (psikolojik testler) yapılması ile, sürücülerin güvenli bir sürüş davranışı benimsemesine rehberlik edilebileceğini göstermiş̧tir [4].

Sürücü becerileri ve davranışlarının trafik güvenliğine önemli bir etkisi vardır. Sürücü becerileri, bilgi işleme ile motor becerileri işaret ederken, sürücü davranışları ise, sürücülerin trafikte yaptıkları olup, bu bağlamda kasıtlı ve kasıtlı olmayan yanlış sürücü davranışları mevcuttur. Kasıtlı olmayan davranışlar, sinyal kullanmak isterken silecekleri çalıştırmak, şerit değiş̧irirken dikiz aynasını kontrol etmemek gibi dikkat ve hafıza kusurlarından ya da kural ve bilgi temelli hatalardan oluşurken; kasıtlı sapkın davranışlar ise ihlaller olarak bilinen hız sınırını aşmak, takip uzaklığını korumamak, diğer sürücülere kızıp bu kızgınlığı belirtmek için korna çalmak, ilgili taşıtı yakın takip etmek gibi davranışlardır. Trafikte kaçınma davranışı ise bu tür riskli davranışların ortaya çımasıyla ilişkilendirilebilecek bir unsur olarak ortaya çıkmaktadır. Sürücülerin hava durumu, trafik durumu, kaza geçmişi gibi pek çok nedenden dolayı kaçınma davranışı gösterdikleri görülmektedir. Yapılan bu çalışmanın amacı, sürücülerin demografik özelliklerinin kaçınma davranışıyla ilişkilerinin belirlenmesine yöneliktir. Yaş ve cinsiyet kontrol değişkeni olarak ele alınırken, kişilerin trafikle bağlantılı demografik değiş̧enleri olan ehliyet süresi, ömür boyunca kat edilen yol miktarı, taşı kullanma sıklığı, aktif kaza sayısı ve kendisinin ya da yakınının geçirdiği ölümlü/yaralanmalı kaza sayısı değişkenleri analizde yer almıştır. Yaş ve cinsiyetin trafikten kaçınma ile negatif, ölümlü/yaralanmalı kaza geçmişinin ise pozitif ilişkili olduğu bulunmuştur. Ayrıca kadın sürücülerin trafikte daha fazla kaçınma davranışı gösterdiği de araştırma sonuçlarından biri olarak görülmüştür [5].

Literatürde ayrıca, sürücülük becerileri ile güvenli araç kullanma becerileri kavramları arasında negatif bir ilişki olduğu görülmektedir. Örneğin, en fazla trafik kazası ve cezası olan grubun yüksek araç kullanma becerisi ve düşük güvenli araç kullanma becerisi puanı alanlar olduğu görülmüştür. Buradan hareketle, güvenlik yönelimli araç kullanma becerileri ile desteklenmemiş, sadece sürücülük becerisini arttırmaya yönelik uygulamaların, beklenenin aksine kaza ya da ceza sayısını arttırma potansiyeline sahip olabileceği ifade edilebilir [6].

Amerika'da Ulusal Karayolu Trafik Güvenliği İdaresi (NHTSA)'ne göre sinirli sürüş belirtileri; hız sınırını aşma, çok yakın takip etme, kararsız ve güvensiz şerit değiştirme, hatalı sinyal vererek ya da sinyal vermeden şerit değiştirme, trafik kontrol cihazlarına uymama(dur işaretleri, yol ver, trafik 1şıkları, demiryolu geçiş sinyalleri vs.) olarak kategorize edilmiştir. Yine NHTSA'ya göre kırmızı ışıkta geçme en tehlikeli sinirli sürüş hareketlerinden biri olarak görülmektedir. Ayrıca bu kurum tarafından; birden fazla kural ihlalinin kaza riskini arttıracağından, bu ihlalleri işleyen sürücülerin yasalarla cezalandırılması, konunun ciddiyetinin bu şekilde sağlanması gerektiği önerilmektedir [7]. 


\section{Türkiye'de Trafik Kazaları}

Ülkemizin trafik kazalarında göreceli olarak pozisyonunu görebilmek için Avrupa ülkeleri ile karşılaştırma yapılabilir. Türkiye'de bin kişiye düşen otomobil (özel araç) sayısı 150 iken, Avrupa Birliği'ne üye olan ülkeler (AB-28)'de bin kişiye düşen otomobil ortalama sayısı 516'dır. Bu farka rağmen ülkemizde bir milyon otomobile düşen ölü sayısı 438, AB-28 de 96 olarak gerçekleşmektedir. Ayrıca ülkemizde bir milyon kişiye düşen ölü sayısı 66 iken, AB-28 için bir milyon kişiye düşen ölü sayısı 49'dur. Ülkemizin trafik kazalarında en güncel durumunu görmek için 2019 yılı trafik kaza istatistikleri incelenmiştir.

2019 yılında, Türkiye'de gerçekleşen 1.168.144 trafik kazasında, 2524 kişinin olay yerinde, 2949 kişinin ise kaza sonrası (30 gün içinde) kazanın etkisiyle hayatını kaybetmiş, 283.234 kişi de yaralanmıştır [8].

\section{1. Ölümlü ve Yaralanmalı Kazalar}

2019 yılına ait ölümlü ve yaralanmalı kazalardaki kusur oranları incelendiğinde, \% 97,65 insan faktörü (\% 88.89 sürücü, \% 7,92 yaya ve \% 0,85 yolcu), \% 2,05 taşıt ve \% 0,30 ile yol kusurunun raporlandığı görülmüştür.

Gerçekleşen ölümlü kazaların \% 50 ile yerleşim yerleri ve yerleşim yeri dışı arasında yaklaşık olarak eşit dağıldığı görülmektedir. Bununla beraber, yaralanmalı kazaların ise \%77'si yerleşim yerinde, \%23'ü yerleşim yeri dışında gerçekleşmiştir.

Yolun geometrik özelliklerine göre yerleşim yeri ve yerleşim yeri dışında ölümlü ve yaralanmalı (toplam 132.683 kaza) kazaların yoğunlaştığı kesimlere bakıldığında;

- Yatay güzergaha göre; yerleşim yeri içinde ve dışında kazaların büyük çoğunluğunun düz yolda (sırasıyla; \% 89,98 ve \% 84,28), geriye kalanların ise dönemeçlerde gerçekleştiği,

- Düş̧ey güzergaha göre; yerleşim yeri içinde ve dışında kazaların büyük çoğunluğunun eğimsiz yolda (sırasıyla; \% 81,10 ve \% 77,60), geriye kalan kazaların eğimli, tehlikeli eğimli, tepe üstü kısımlarda gerçekleştiği,

- Kavşak durumuna göre; yerleşim yeri içinde ve dışında kazaların çoğunluğunun kavşağın olmadığı kesimlerde (sırasıyla; \% 55,51 ve \% 62,45), geriye kalan kazaların dört yönlü, üç yönlü (T ve Y), dönel, ve köprülü kavşaklarda gerçekleştiği,

- Geçit durumuna bakıldığında ise; yerleşim yeri içinde ve dışında kazaların çoğunun geçit olmayan yerlerde (sırasiyla; \% ,27 ve \% 90,51), geriye kalan kazaların ise en fazla yaya geçidi olan kısımlarda (sırasıyla \% 10,64 ve \% 8,59) meydana geldiği,

belirlenmiştir.

Her bir ölçüte göre yapılan bu analizlerde, dağılımlar, toplam ölümlü ve yaralanmalı kaza sayısı olan yerleşim yerinde 132.683, yerleşim yeri dışında 42.213 kaza üzerindendir [8].

Kaza oluş türlerine göre kazalar incelendiğinde; yerleşim yeri için dağılım Şekil 1'de, yerleşim 
yeri dışı için dağılım ise Şekil 2'de verilmiştir.

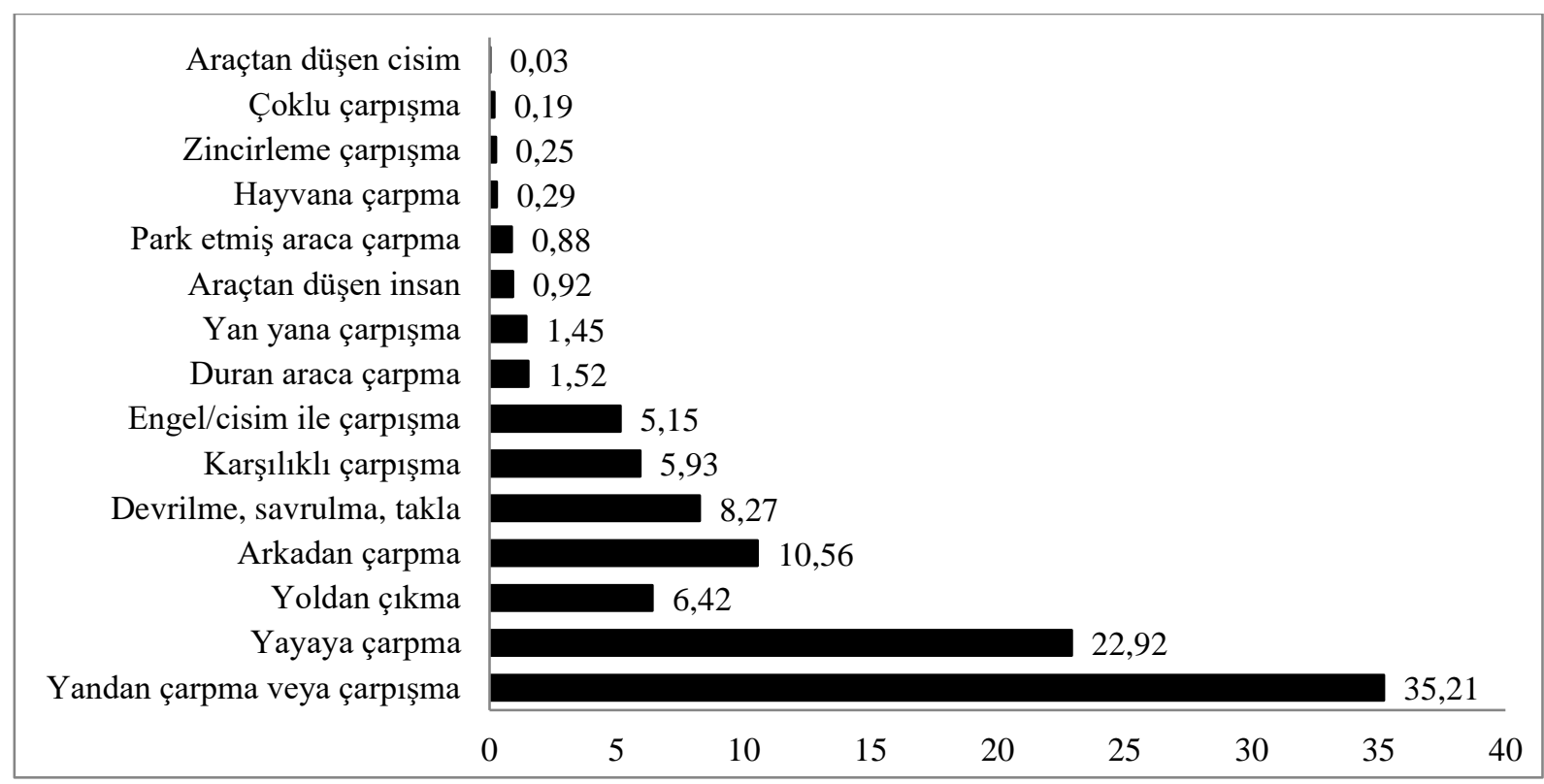

Şekil 1. Yerleşim yerinde kaza oluş türleri dağı̆lımı

Yerleşim yerindeki kaza oluş türlerine bakıldığında (Şekil 1), \% 35,21 oranıyla en fazla yandan çarpma veya çarpışma, ondan sonrada yine önemli bir oran olan \% 22,92 ile yayaya çarpma türünde ki kazaların, problemin yapısında önemli bir katkıya sahip oldukları görülmektedir.

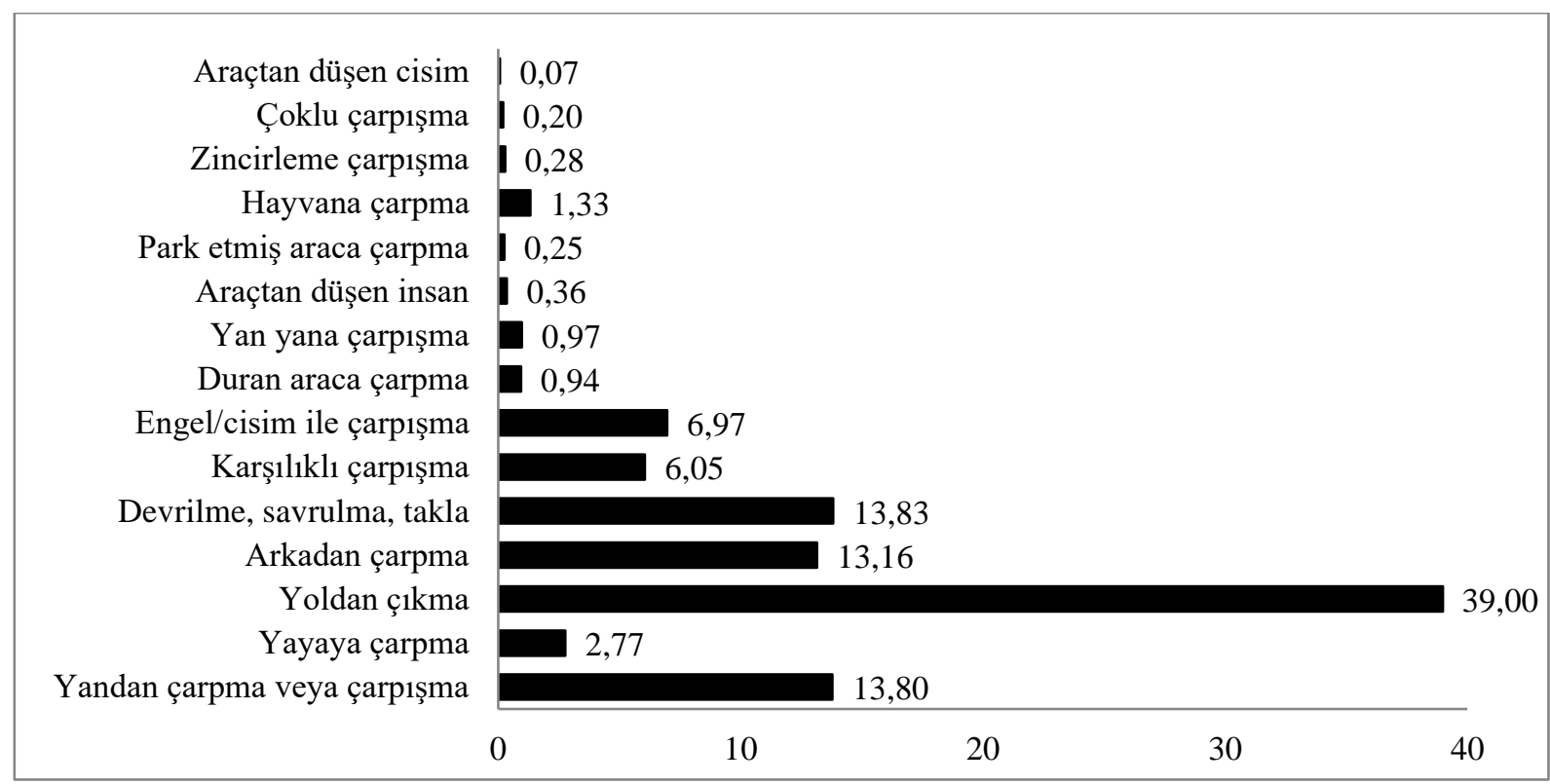

Şekil 2. Yerleşim yeri dışında kaza oluş türleri dağılımı

Yerleşim yeri dışında ise \% 39 oranıyla en çok yoldan çıkma, sonrasında \% 13,83 oranıyla devrilme-savrulma-takla, arkadan çarpma ve \% 13.80oranıyla da yandan çarpma türünde kazaların 
meydana geldiği belirlenmiştir.

Engel, cisim ile çarpışma ve karşılıklı çarpışma türünde kazalarında önemli bir orana $(\% 6,97)$ sahip olduğu görülmektedir.

2010 ile 2019 yılları arasında ortalama sürücü kusurları \% 89,5, yaya kusurları \% 8,72, yolcu kusurları \% 0,53, taşıt kusurları \% 0,68 ve yol kusurları \% 0,53 olarak bulunmuştur. Bu oranlara göre, gerçekleşen kazaların çok büyük çoğunluğunun sürücü hatalarından kaynaklandığg anlaşılmaktadır.

Şekil 3'te yerleşim yerinde görülen sürücü hatalarında, taşıt hızını yol, hava ve trafiğin gerektirdiği koşullara uydurmama ve kavşak, geçiş önceliğine uymama hataları sonucunda, yandan çarpma ve yayaya çarpma hata oranlarının yüksek olması durumu oluşmuştur.

Şekil 4'te ise yerleşim yeri dışında görülen sürücü hatalarında, taşıt hızını yol, hava ve trafiğin gerektirdiği koşullara uydurmama ve şerit ihlali yapma hataları sonucunda, yoldan çıkma durumu oranının fazla olmasının nedeni, şehirlerarasında hız sınırlarının şehir içinden çok daha fazla olması ile ilişkilendirilebilir.

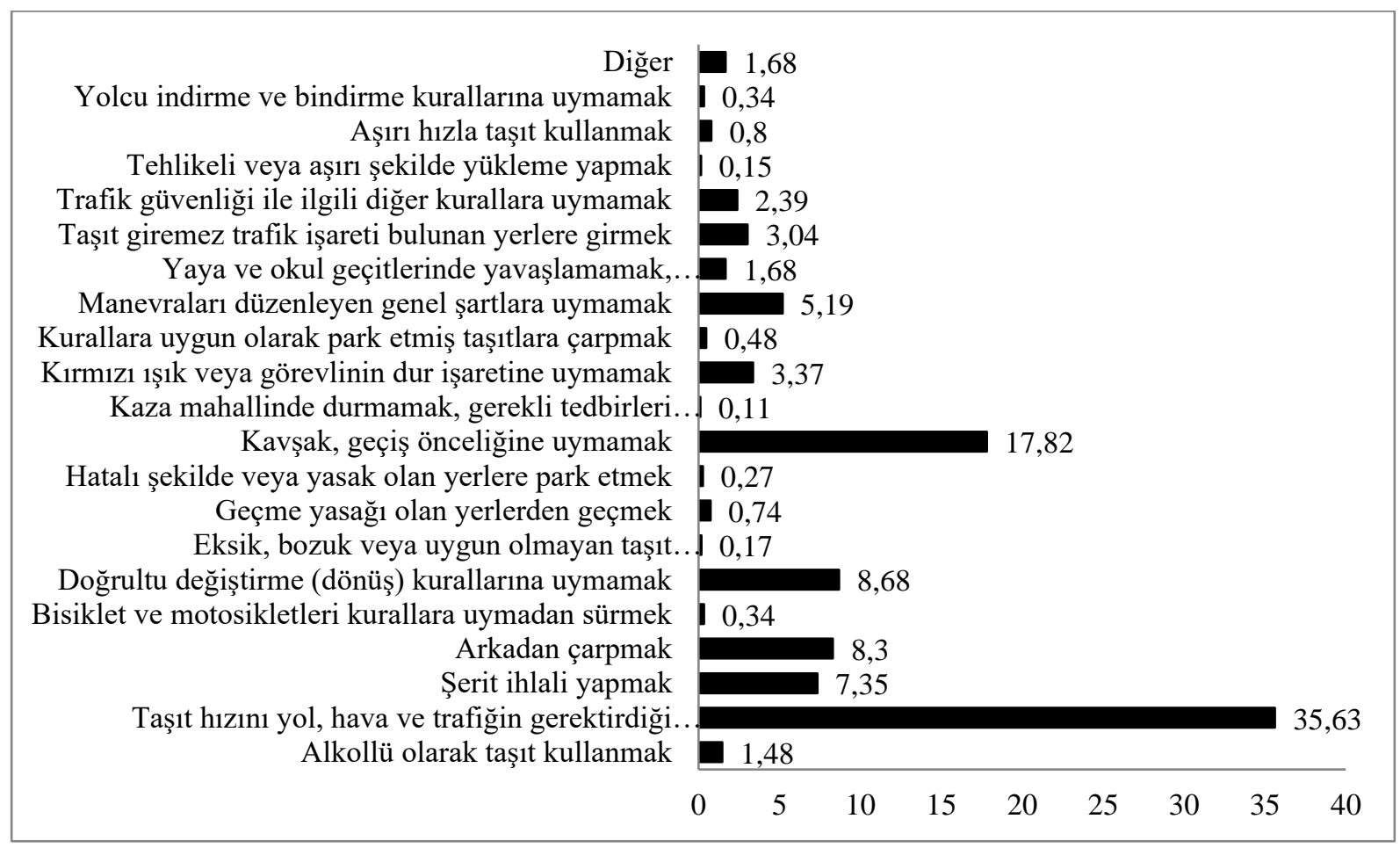

Şekil 3. Yerleşim yerinde sürücü hataları dağılımı

Yerleşim yeri içinde sürücü hatalarına bakıldığında en yüksek kusurun \% 35,63 oranıyla taşıt hızını yol, hava ve trafiğin gerektirdiği koşullara uydurmama olduğu, bu hatayı \% 17,82 oranıyla kavşak, geçiş önceliğine uymamanın izlediği görülmektedir. 


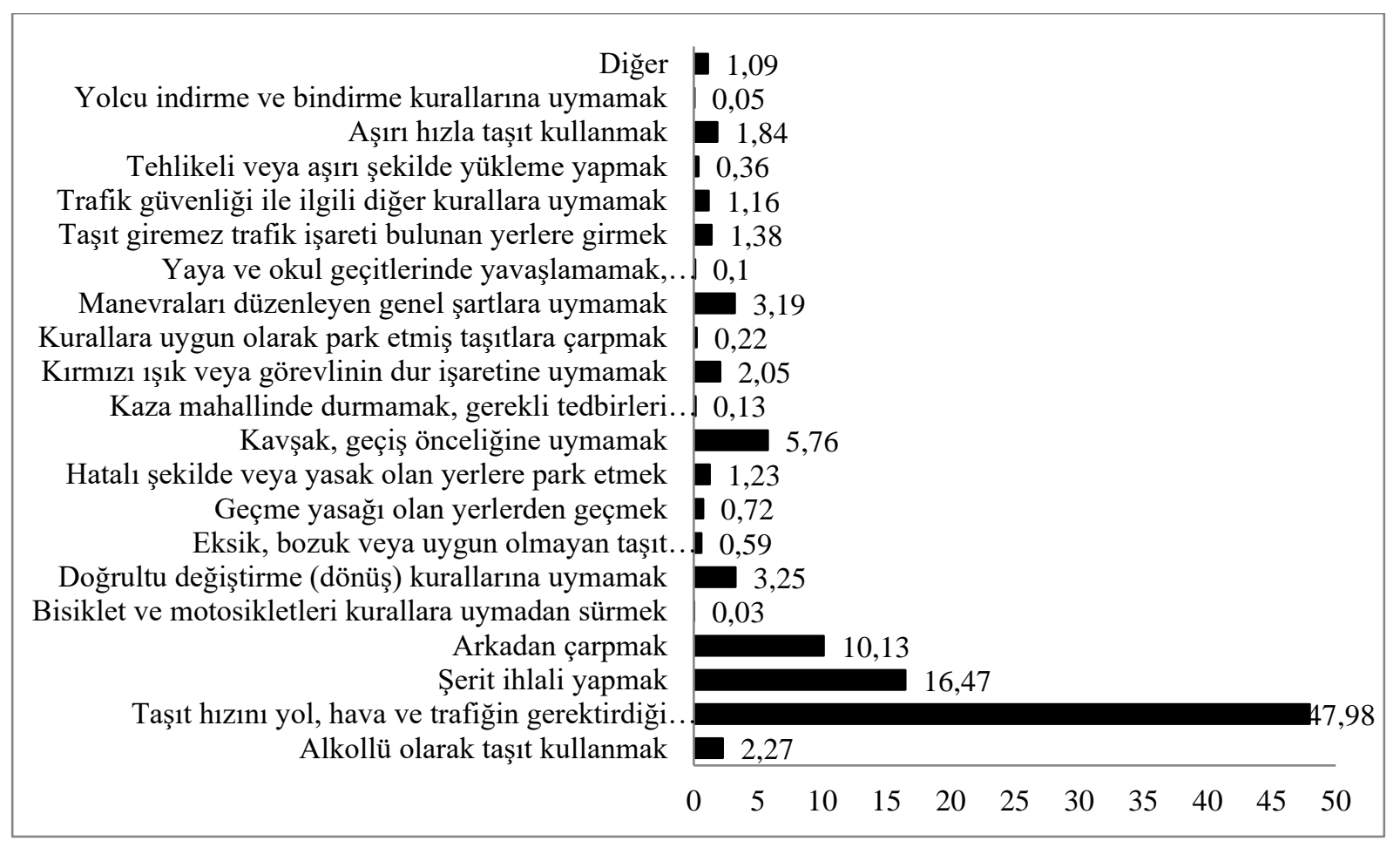

Şekil 4. Yerleşim yeri dışında sürücü hataları dağılımı

Yerleşim yeri dışında sürücü hatalarına bakıldığında burada da en büyük hataların sırası ile $\% 47,98$ oranıyla taşıt hızını yol, hava ve trafiğin gerektirdiği koşullara uydurmama, \% 16,47 oranıyla şerit ihlali yapma, \% 10,13 oranıyla da arkadan çarpma olduğu gözlemlenmektedir.

\section{Sonuçlar}

Can kayıpları, ciddi yaralanmalar gibi büyük, hafif yaralanmalar ve maddi hasarlar gibi nispeten daha küçük olumsuz etkileri tüm dünyada olduğu gibi ülkemizde de yadsnamayacak bir gerçek olarak karşımızda duran trafik kazalarını azaltmaya yönelik çalışmalar hayati önem taşımaktadır.

Yapılacak olan trafik kazaları analizleriyle;

- hangi tip taşıt sürücülerinin (tır, taksi, minibüs vs.) hangi tip kazaya yatkın (neden) oldukları,

- en çok trafik kazalarının yaşandığı yol kesimlerinde (kavşak), hangi hataların kazalara neden olduğu,

- EDS, radar, trafik polisi denetimi gibi cezai yaptırım uygulayıcılarının etkisi,

- ramak kala kazalar incelenip, sürücülerle anket yapılarak kaçınma davranışları,

- hangi tip (sürücü özellikleri verileri toplanarak) sürücülerin hangi tip davranışlarından kaçınma halinde oldukları, hangi durumlarda sapkın davrandıklarının belirlenmesine dönük,

özel alan çalışmalarının yapılması, gerek kaza sayılarının gerekse de ortaya çıkmaları durumunda şiddetlerinin azalmasına katkı sunacaktır. 
Ülkemizde henüz trafik güvenliği kavramı benimsenmediğinden, uyulması gereken kurallar tam olarak bilinip uygulanmadığından insan unsuru yalnızca bireysel sürücü özelliklerine bakılarak incelenemez. Sapkın sürücü davranışlarına daha da eğilim göstermeye yönelen sürücülerin bulunduğu trafik ortamına ait durumlar kapsamlı bir şekilde göz önünde bulundurulmalıdır. Yapılacak çeşitli gözlem, anket gibi veri toplama araçları sonucunda sürücülerin trafikteki yanlışlarının bağlantıları çözümlenebilecek ve uygun önlemler alınabilecektir [9].

Makale içeriğinde de ortaya konulduğu gibi, kaza oluşumlarına ve türlerine etki eden çok yönlü çapraşık parametre ve etkilerin belirlenmesine dönük olarak veri madenciliği çalışmasının yapılması ve trafik kazalarının yapısının bu anlamda daha derinlikli ortaya konulması, bir sonraki aşamada yapılacak olan analitik çalışma ve araştırma sürecinin temelini oluşturacaktır.

\section{Kaynaklar}

[1] WHO, https://www.who.int/news-room/fact-sheets/detail/road-traffic-injuries (erişim tarihi: 07.10.2020).

[2] Yu S, Jia Y, Sun D. Identifying Factors that Influence the Patterns of Road Crashes Using Association Rules: A case Study from Wisconsin, United States. Sustainability 2019;11:1925. https://doi.org/10.3390/su11071925.

[3] Shahverdy M, Fathy M, Berangi R, Sabokrou M. Driver behavior detection and classification using deep convolutional neural networks. Expert Systems with Applications 2020;149:113240. https://doi.org/10.1016/j.eswa.2020.113240.

[4] Alavi SS, Mohammadi MR, Souri H, Kalhori SM, Jannatifard F, Sepahbodi G. Personality, Driving Behavior and Mental Disorders Factors as Predictors of Road Traffic Accidents Based on Logistic Regression n.d.;42:8.

[5] Özkan Ö, Öz B. Sürücü Demografik Özelliklerinin Trafikte Kaçınma Davranışı ile İlişkisi. Trafik ve Ulaşım Araştırmaları Dergisi 2019;2:108-22. https://doi.org/10.38002/tuad.621367.

[6] Sümer N, Özkan T. Sürücü Davranışları, Becerileri, Bazı Kişilik Özellikleri ve Psikolojik Belirtilerin Trafik Kazalarındaki Rolleri 2002:26.

[7] US Dept of Transportation National Highway Traffic Safety Admin, United States of America. Aggressive Driving Enforcement: Strategies for Implementing Best Practices. United States of America: US Dept of Transportation National Highway Traffic Safety Admin Washington, DC 20590; 2000. 
[8] TrafikKazalariOzeti2019. KGM 2020.

https://www.kgm.gov.tr/SiteCollectionDocuments/KGMdocuments/Trafik/TrafikKazalariOzeti2 019.pdf (erişim tarihi: 01.09.2020).

[9] Sümer N, Lajunen T, Özkan T. Sürücü Davranişlarinin Kaza Riskindeki Rolü: İhlaller ve Hatalar 2002. 